\title{
Bilirubin as a New Biomarker of Diabetes and its Microvascular Complications
}

\author{
Takeshi Nishimura , Masami Tanaka, Risa Sekioka and Hiroshi Itoh \\ Department of Internal Medicine, School of Medicine, Keio University, Tokyo, Japan
}

*Corresponding author: Takeshi Nishimura, Department of Internal Medicine, School of Medicine, Keio University 35 Shinanomachi, Shinjuku-ku, Tokyo 160-8582, Japan, Tel: 81-3-5363-3797; Fax: 81-3-3359-2745; E-mail: t-nishimura128@z6.keio.jp

Rec date: Feb 06, 2016; Acc date: Feb 12, 2016; Pub date: Feb 15, 2016

Copyright: (C) 2016 Nishimura T, et al. This is an open-access article distributed under the terms of the Creative Commons Attribution License, which permits unrestricted use, distribution, and reproduction in any medium, provided the original author and source are credited.

\section{Commentary}

Hyperglycemia is the hallmark of diabetes mellitus [DM]; it activates certain biochemical pathways leading to micro- and macrovascular complications in diabetic patients [1]. Moreover, hyperglycemia generates oxidative stress and causes free radicalmediated lipid peroxidation [2,3]. In turn, the oxidative stress causes endothelial dysfunction, and has been suggested as one of the important mechanisms underlying the onset and progression of diabetic vascular complications [4].

Bilirubin, the end product of heme catabolism, is known to exhibit strong anti-oxidant and anti-inflammatory properties on the vasculature $[5,6]$. It has been reported that the prevalence of vascular complications in diabetic patients with Gilbert syndrome, a congenital hyperbilirubinemia, is lower compared with in those without this syndrome [7]. Further, bilirubin has been shown to reduce the oxidant levels in wounds and to accelerate wound healing in diabetic rats [8]. In accordance with the results of this previous animal study, several literatures have reported the association between diabetic microvascular complications and bilirubin by comparing serum bilirubin concentrations in diabetic patients with and without microvascular complications such as neuropathy [9], nephropathy [10], and retinopathy [11,12]. However, out of these three microvascular complications, prospective findings have only been acquired for nephropathy $[13,14]$. Recent prospective cohort studies have demonstrated that a low serum bilirubin concentration is a novel risk factor for the development of albuminuria in type $2 \mathrm{DM}$ patients $[13,14]$. In other words, with regards to neuropathy and retinopathy, no causal relationships with bilirubin have yet been determined, owing to the cross-sectional and retrospective natures of the studies on the topic. Interestingly, elevated bilirubin levels have been shown to be a protective determinant for the incidence of type 2 DM per se [15].

Recently, we reported that type $1 \mathrm{DM}$ patients with retinopathy and nephropathy showed a lower serum total bilirubin concentration than those without these complications [16,17]. We also reported that indirect bilirubin showed a stronger association with nephropathy than total bilirubin in type 1 diabetics [16]. However, other than our observations, reports about the relationships between bilirubin and diabetic complications have been restricted to type 2 diabetics so far. Concerning the types of bilirubin [total, direct, or indirect], the concentrations of all three types have been shown to be lower when retinopathy is present in type $2 \mathrm{DM}$ patients [18], whereas no reports other than ours are available on type $1 \mathrm{DM}$ patients. Whether bilirubin plays important roles in the onset and progression of vascular complications and what type of bilirubin is important in type $1 \mathrm{DM}$ patients are exciting and important clinical questions. In order to elucidate the pathophysiological role of bilirubin in type $1 \mathrm{DM}$, our results should be verified in large-scale, prospective studies.

\section{References}

1. Takayanagi R, Inoguchi T, Ohnaka K (2011) Clinical and experimental evidence for oxidative stress as an exacerbating factor of diabetes mellitus. J Clin Biochem Nutr 48: 72-77.

2. Likidlilid A, Patchanans N, Peerapatdit T, Sriratanasathavorn C (2010) Lipid peroxidation and antioxidant enzyme activities in erythrocytes of type 2 diabetic patients. J Med Assoc Thai 93: 682-693.

3. Su Y, Liu XM, Sun YM, Jin HB, Fu R, et al. (2008) The relationship between endothelial dysfunction and oxidative stress in diabetes and prediabetes. Int J Clin Pract 62: 877-882.

4. Brownlee M (2001) Biochemistry and molecular cell biology of diabetic complications. Nature 414: 813-820.

5. Stocker R, Yamamoto Y, McDonagh AF, Glazer AN, Ames BN (1987) Bilirubin is an antioxidant of possible physiological importance. Science 235: 1043-1046.

6. Mazzone GL, Rigato I, Ostrow JD, Bossi F, Bortoluzzi A, et al. (2009) Bilirubin inhibits the TNFalpha-related induction of three endothelial adhesion molecules. Biochem Biophys Res Commun 386: 338-344.

7. Inoguchi T, Sasaki S, Kobayashi K, Takayanagi R, Yamada T (2007) Relationship between Gilbert syndrome and prevalence of vascular complications in patients with diabetes. JAMA 298: 1396-1400.

8. Ram M, Singh V, Kumar D, Kumawat S, Gopalakrishnan A, et al. (2014) Antioxidant potential of bilirubin-accelerated wound healing in streptozotocin-induced diabetic rats. Naunyn Schmiedebergs Arch Pharmacol 387: 955-961.

9. Kim ES, Lee SW, Mo EY, Moon SD, Han JH (2015) Inverse association between serum total bilirubin levels and diabetic peripheral neuropathy in patients with type 2 diabetes. Endocrine 50: 405-412.

10. Fukui M, Tanaka M, Shiraishi E, Harusato I, Hosoda H, et al. (2008) Relationship between serum bilirubin and albuminuria in patients with type 2 diabetes. Kidney Int 74: 1197-1201.

11. Yasuda M, Kiyohara Y, Wang JJ, Arakawa S, Yonemoto K, et al. (2011) High serum bilirubin levels and diabetic retinopathy: the Hisayama Study. Ophthalmology 118: 1423-1428.

12. Sekioka R, Tanaka M, Nishimura T, Itoh H (2015) Serum total bilirubin concentration is negatively associated with increasing severity of retinopathy in patients with type 2 diabetes mellitus. J Diabetes Complications 29: 218-221.

13. Mashitani T, Hayashino Y, Okamura S, Tsujii S, Ishii H (2014) Correlations between serum bilirubin levels and diabetic nephropathy progression among Japanese type 2 diabetic patients: a prospective cohort study (Diabetes Distress and Care Registry at Tenri [DDCRT 5]). Diabetes Care 37: 252-258.

14. Toya K, Babazono T, Hanai K, Uchigata Y (2014) Association of serum bilirubin levels with development and progression of albuminuria, and decline in estimated glomerular filtration rate in patients with type 2 diabetes mellitus. J Diabetes Invest 23: 228-235 
Citation: Nishimura T, Tanaka M, Sekioka R, Itoh H (2016) Bilirubin as a New Biomarker of Diabetes and its Microvascular Complications. Biochem Anal Biochem 5: 245. doi:10.4172/2161-1009.1000245

Page 2 of 2

15. Abbasi A, Deetman PE, Corpeleijn E, Gansevoort RT, Gans RO, et al. (2015) Bilirubin as a potential causal factor in type 2 diabetes risk: A Mendelian randomization study. Diabetes 64: 1459-1469.

16. Nishimura T, Tanaka M, Sekioka R, Itoh H (2015) Serum bilirubin concentration is associated with eGFR and urinary albumin excretion in patients with type 1 diabetes mellitus. J Diabetes Complications 29: 1223-1227.
17. Sekioka R, Tanaka M, Nishimura T, Itoh H (2015) Low serum total bilirubin concentration in patients with type 1 diabetes mellitus complicated by retinopathy and nephropathy. Diabetology International 6: 300-305.

18. Dave A, Kalra P, Gowda BH, Krishnaswamy M (2015) Association of bilirubin and malondialdehyde levels with retinopathy in type 2 diabetes mellitus. Indian J Endocrinol Metab 19: 373-377. 